\title{
Después del CAS ¿Cómo debe contratar la administración pública? Propuesta de la contratación laboral temporal o sujeta a modalidad ante la derogación progresiva del Decreto Legislativo 1057.
}

\author{
Rebeca Karina Aparicio Aldana ${ }^{1}$
}

\section{INFORMACIÓN DEL ARTÍCULO}

\section{Historia del artículo:}

Recibido el 10 de abril de 2012

Aceptado el 15 de mayo de 2012

\section{Palabras claves:}

Administración pública

contratos sujetos a modalidad

contrato de obra o servicio

contratos de naturaleza temporal

contratos de naturaleza empresarial

\author{
RESUMEN
}

\begin{abstract}
El 06 de abril del 2012, se publicó la Ley 29849 cuyo fin es la eliminación paulatina del Contrato Administrativo de Servicios. Si, a pesar de los penosos pronósticos que aseguran que tal eliminación no se producirá, esta llega a concretarse, la pregunta que se formulan las administraciones públicas es ¿cómo podrán contratar temporalmente a trabajadores, sin incluirlos en la carrera administrativa y sin incurrir en la desnaturalización del contrato? La respuesta a esta interrogante supone comprender los contratos temporales y su ajuste al complejo sistema de las relaciones laborales de la administración pública. Este artículo analizará los contratos sujetos a modalidad estableciendo sus efectos y su uso pertinente en la administración pública. Espero disculpen la referencia al derecho laboral administrativo español, este trabajo es un extracto de la tesis con la que obtuve el grado de Magister en Derecho del Trabajo en la Universidad Rey Juan Carlos de Madrid.
\end{abstract}

After the CAS. How should you hire the Public Ddministration? Proposal for temporary employment or subject to modality before the progressive repeal of DL. 1057.

\section{Introducción}

En la presente investigación, el análisis de los contratos sujetos a modalidad, tiene por finalidad brindar al lector y en especial a la administración pública, una salida jurídica ante la eliminación del Contrato administrativo de servicios, a través de la contratación laboral temporal. El uso de este tipo de contratos, permitiría, a la administración pública peruana, una vez que deba prescindir del CAS, contratar personal para realizar actividades de carácter extraordinario o no permanente, sin desconocer los derechos laborales de aquellos que desempeñen estas funciones, asegurando la existencia de un marco de legalidad y de respeto de los derechos fundamentales.

Los estudios sobre la aplicación de contratación laboral temporal en la Administración pública peruana son escasos, por no decir inexistentes, y por ello, este artículo constituye un esfuerzo comparativo entre la doctrina científica y jurisprudencia peruana, con la doctrina científica y jurisprudencia española. La decisión de realizar este trabajo comparativo teniendo como espejo a la doctrina científica y jurisprudencia española se asienta en que en España se ha desarrollado y analizado concienzudamente la contratación laboral en las administraciones públicas ofreciendo, en líneas generales, un visión amplia de sus posibilidades de acción y ejecución dentro de la administraciones públicas y sirviendo de mesa de ensayo para comprobar que la aplicación de este tipo de contratos en la administración pública es posible.

\section{CONTRATOS DE OBRA O SERVICIO}

1.1. Contrato de obra determinada o servicio específico El contrato por obra o servicio determinado es aquel que se celebra cuando resulte necesario que una persona realice una

\footnotetext{
1 Doctoranda y Máster en Derecho del Trabajo y la Seguridad Social a través de la Jurisprudencia por la Universidad Rey Juan Carlos de Madrid - España, Máster en Derecho con mención en Derecho Constitucional y abogada por la Universidad de Piura, profesora de la Universidad Católica Santo Toribio de Mogrovejo. Área de Historia y Filosofía del derecho. Chiclayo (Perú).
} 
obra o servicio determinado con autonomía y sustantividad propia dentro de la actividad de empresa y cuya ejecución aunque limitada en el tiempo, sea en principio de duración incierta ${ }^{2}$.

De acuerdo a lo establecido en el artículo $63^{\circ}$ de la Ley de Productividad y Competitividad Laboral peruana el contrato de obra o servicio específico es aquel celebrado, entre un empleador y un trabajador con el objeto previamente establecido, cuya duración será la que resulte necesaria ${ }^{3}$. Por ejemplo, es factible que, frente a una expropiación realizada de acuerdo con la Ley 27117 "Ley de expropiaciones", además de la indemnización justipreciada, se compense a los afectados con su reubicación en módulos habitacionales. La actividad de construcción de módulos con fines de vivienda, puede que no sean una labor propia de la Administración pública, sujeto activo de la expropiación, pero producida la necesidad y llegando a este acuerdo con los sujetos pasivos la expropiación, la administración podrá mediante el contrato de obra determinada, contratar personal para realizar esta actividad, mientras que se cuente con presupuesto para tal fin, en tanto la actividad realizada es limitada pero de duración incierta, pues dependerá del manejo del presupuesto público.

Dadas las características de esta forma de contratación, es obvio, que el contrato de obra o servicio específico no podrá ser utilizado para cubrir necesidades de carácter permanente del organismo público. Asimismo, dada la posición especial de la administración, es posible considerar dentro de este tipo de contratos, la existencia de un programa público de actuación específica, por ejemplo, cuando dentro de una Administración pública se subvenciona la realización de una actividad excepcional, no ordinaria, ni común de la administración ${ }^{4}$. Así, puede ser que por política estatal se disponga mediante ley que todas las administraciones

\footnotetext{
2 Sempere Navarro, Antonio (Dir.) y Martín Jiménez, Rodrigo (Coord.), Los contratos temporales, Thomson-Aranzandi, Cizur Menor, p. 78.

${ }^{3}$ STS 4 diciembre 1992 (RJ 1992, 10421) , 5 julio 1999 (RJ 1999, 6794) , STSJ Andalucía - Granada 18 junio 2001 ( AS 2001, 821) , Cataluña 5 junio 2001 (AS 2001, 3484)

${ }^{4}$ Sempere Navarro, Antonio y Quintanilla Navarro, Raquel, La contratación laboral en las administraciones públicas, Thomson- Aranzandi, Pamplona, 2003, p. 79

${ }^{5}$ Proyecto que tiene como fin Aumentar la producción, productividad y rentabilidad de 50 mil hectáreas. bajo riego, reintegrando 31 mil hectáreas. a la producción, e incorporar 19 mil hectáreas. de tierras nuevas, mediante el trasvase de $335 \mathrm{MMC}$ de agua del río Huancabamba al río Piura e Incrementar la producción de energía hidráulica en base a las aguas trasvasadas y las caídas de más de 1,200 metros, mediante la instalación de dos centrales hidroeléctricas de $150 \mathrm{MW}$ cada una, en Cashapite y Gramadal. Gobierno Regional Piura, "Proyecto especial de Irrigación e Hidroenergético del Alto Piura", http://www.peihap.gob.pe/indexax3.php?pagina=objetivos.html, ubicado el 06 de marzo del 2001.

${ }^{6}$ Este proyecto tiene como fin planificar, ejecutar, supervisar y administrar la ejecución de obras de riego, proponer el desarrollo de la agricultura, impulsar el proceso de inversión privada en la agricultura y contribuir a elevar el nivel de vida de los agricultores en el ámbito de su influencia. En Gobierno Regional de Piura, "Proyecto Especial Chira Piura", http://www.chirapiura.gob.pe/principal.php, ubicado el 06 de marzo del 2001.

${ }^{7}$ Artículo 9 de la Ley Orgánica de Gobiernos Regionales, Ley 27867.
}

públicas ingresen a un proceso de saneamiento físico legal de sus bienes muebles o inmuebles destinando, por un tiempo determinado, una partida presupuestaria para contratación de personal especializado en la ejecución de estas actividades.

Esta forma de contratación no debe confundirse con la contratación de personal para proyectos especiales a cargo de administraciones específicas, como por ejemplo los Gobiernos Regionales. Los proyectos especiales, generalmente constituyen unidades ejecutoras de funciones propias de la administración, por ejemplo, el Proyecto Especial de Irrigación e Hidroenergético del Alto Piura ${ }^{5}$ o el Proyecto especial Chira Piura ${ }^{6}$, ambos proyectos ejecutan una función propia de los Gobiernos Regionales, la de promover el desarrollo socioeconómico de la región, y de promover y regular, entre otras actividades y/o servicios, acciones en favor de la agricultura, industria, agroindustria, comercio, energía, vialidad, y medio ambiente ${ }^{7}$. Estos proyectos se caracterizan por su gran envergadura por lo que la administración desconcentra la actividad siendo la duración del proyecto usualmente incierta, y muchas veces superior a 10 o 20 años $^{8}$. Por tal motivo y dado que los contratos sujetos a modalidad no pueden ser renovados por un periodo mayor de cinco años de acuerdo a lo establecido en el artículo $74^{\circ}$ de la Ley de Productividad y Competitividad laboral y en el caso particular de los contratos por obra y servicio específico, por decisión jurisprudencial ${ }^{9}$ no pueden extenderse de ocho años, la forma de contratación adecuada será la de contratación fija e indefinida dado que la actividad corresponde al ejercicio de una función propia de la administración y el término de dicha contratación vendrá determinado por una causa objetiva, la culminación de los objetivos del proyecto ${ }^{10}$.

\footnotetext{
${ }^{8}$ El Proyecto de irrigación Olmos Tinajones por ejemplo tiene a la fecha 50 años y el Proyecto Chira Piura 40 años de trabajo ininterrumpido.

${ }_{9}^{9}$ Casación 1004-2004-Tacna Moquegua de fecha 05 de enero del 2007 y Casación 1809-2004- Lima de fecha 20 de enero del 2006

${ }^{10}$ Tanto, trabajadores de proyectos especiales, como aquellos contratados por obra o servicio específico se encontraban regulados bajo la Ley 24041. Esta norma, como ya hemos señalado anteriormente, establecía que los servidores públicos contratados para labores de naturaleza permanente, con más de un año ininterrumpido de servicios, no podían ser cesados ni destituidos sino por las causas justas, no encontrándose incluidos dentro de los beneficios de esta ley los servidores públicos contratados para desempeñar trabajos por obra determinado o labores en proyectos de inversión, proyectos especiales, en programas y actividades técnicas, administrativas y ocupacionales, siempre y cuando sean de duración determinada. Por lo que se consideró que todos aquellos que se encontraban bajo esta modalidad laboral carecían del derecho a estabilidad laboral, por lo que podrían ser despedidos en cualquier momento sin expresión de causa.
}

Sobre esto habría que decir que el derecho a la estabilidad laboral es un derecho constitucionalmente reconocido y en consecuencia ninguna norma legal podría regular de forma contraria al mismo. Es cierto que el momento de inicio del derecho de estabilidad laboral en una relación de trabajo puede venir determinada por ley pero esto no significa que por ley pueda privar de este derecho de manera absoluta como se produce con la Ley 24041 que resulta ser una norma inconstitucional.

Asimismo, muchas veces se consideró que toda relación laboral dentro de un proyecto especial debía incluirse dentro de las excepciones de los beneficios otorgados por esta norma. Pero de una lectura, detenida del artículo segundo de la referida ley parece claro que los únicos excluidos (así 


\section{EL CONTRATO INTERMITENTE Y EL CONTRATO DE TEMPORADA}

Los contratos de servicio intermitente son aquellos celebrados entre un empleador y un trabajador, para cubrir las necesidades de las actividades de la empresa que por su naturaleza son permanentes pero discontinuas. Estos contratos podrán efectuarse con el mismo trabajador, quien tendrá derecho preferencial en la contratación, pudiendo consignarse en el contrato primigenio tal derecho, el que operará en forma automática, sin necesidad de requerirse de nueva celebración de contrato o renovación.

El contrato de temporada, por su parte, es aquel celebrado con el objeto de atender necesidades propias del giro de la empresa o establecimiento, que se cumplen sólo en determinadas épocas del año y que están sujetas a repetirse en períodos equivalentes en cada ciclo en función a la naturaleza de la actividad productiva.

Estos contratos en realidad responden a la naturaleza del contrato fijo y periódico y del contrato fijo discontinuo, regulado por los artículos 12.3 y 15.8 del Estatuto de trabajadores de España, respectivamente. Los contratos fijos periódicos equivalentes al contrato de servicio intermitente son aquellos en los cuales se conoce perfectamente la fecha de inicio de la actividad periódica a realizar mientras que los fijos discontinuos, equivalentes a los contratos de temporada, son aquellos en dónde dada la calidad imprevista del tiempo, se desconoce su fecha de iniciación y en consecuencia estará sujeto a la producción de las condiciones óptimas para que la actividad que es su objeto pueda llevarse a cabo.

Así un ejemplo, el Ministerio de Agricultura tiene a cargo una serie de proyectos de gestión agrícola a través de cultivos diversos, como el mango por ejemplo, que sólo se produce en el norte de Perú entre los meses de noviembre o diciembre hasta marzo, pudiendo extenderse incluso hasta la primera quincena de abril por lo que, en esa determinada época del año será necesaria la contratación de personal por temporada.

Un ejemplo de contrato intermitente es la contratación de personal adicional para la celebración de la Semana Jubilar de distintas localidades de Perú quizás las más hermosas la de Trujillo y Cuzco. Las semanas jubilares se celebran todos los años en el aniversario de creación de las ciudades, por lo que se conoce perfectamente su fecha de inicio y fin, realizándose diversas actividades recreativas, culturales y deportivas. Las actividades además, en líneas generales, son siempre las mismas, por ejemplo, será indispensable la elaboración de un carro alegórico representando a la Municipalidad, es más, se espera su presencia, por lo que cabría la posibilidad de

la exclusión sea inconstitucional) son aquellos que son contratados para proyectos de inversión, proyectos especiales, en programas y actividades técnicas, administrativas y ocupacionales, siempre y cuando sean de duración determinada; contrarios sensu todos aquellos contratados para proyectos especiales de duración incierta sí se encontraban beneficiados por la Ley 24041.

${ }^{11}$ Gonzalo del Rey Rodríguez, Ignacio, El contrato de trabajo a tiempo parcial, Aranzadi, Pamplona, 1998, p. 284. contratación intermitente para la realización en esas fechas de esa actividad.

Por ello, la ubicación de este tipo de contratos dentro de los contratos de naturaleza temporal es inadecuada dado que el carácter periódico o discontinuo no afecta a la duración temporal o indefinida del contrato ${ }^{11}$, es más existiendo en Perú el contrato de ocasión éste parece estar refiriéndose a la intermitencia temporal, y estos contratos a la intermitencia indefinida ya sea periódica o discontinua.

\section{LOS CONTRATOS DE NATURALEZA TEMPORAL}

\subsection{Contrato por necesidades de mercado}

El contrato temporal por necesidades del mercado denominado en la doctrina española contrato eventual cuyo objeto se proyecta sobre la contingencia que supone una necesidad empresarial de atender circunstancias que imposibilitaran a subvenir a ellas mediante el empleo del personal de la empresa, dedicado normalmente, a la atención de la producción permanente u ordinaria de la misma, generalmente constante y no sometida a vaivenes o imprevistos que reclaman una demanda adicional de nueva mano de obra ${ }^{12}$.

El contrato por necesidad del mercado, entonces es aquel que al igual que en el contrato eventual, se celebra con el objeto de atender incrementos coyunturales de la producción, originados por variaciones sustanciales de la demanda en el mercado, aún cuando se trate de labores ordinarias que formen parte de la actividad normal de la empresa y que no pueden ser satisfechas por el personal permanente. La causa objetiva de este contrato deberá sustentarse en un incremento temporal e imprevisible del ritmo normal de la actividad productiva con exclusión de las variaciones de carácter cíclico o de temporada que se producen en algunas actividades productivas de carácter estacional. ${ }^{13}$

El crecimiento de la actividad productiva debe ser excepcional, no existiendo, por tanto, otra forma de atender el incremento experimentado en la demanda de la actividad laboral que mediante la contratación de trabajadores en forma temporal, so pena de sobredimensionar excesivamente la plantilla de la empresa mediante contrataciones indefinidas innecesarias dado el carácter extraordinario de la necesidad de mano de obra para el ordinario funcionamiento de la empresa ${ }^{14}$.

Este incremento productivo es, por lo tanto, únicamente transitorio y es de tal magnitud que la variación en la demanda origina que no pueda ser satisfecha por el personal contratado por tiempo indefinido, por lo que, este contrato sólo podrá ser utilizado en ocasiones extraordinarias

\footnotetext{
${ }^{12}$ Sempere Navarro, Antonio (Dir.) y Martín Jiménez, Rodrigo (Coord.), Ob. cit., p. 122 y en el mismo sentido Camps Ruíz, Luis Miguel, La contratación laboral temporal, 2da. ed., Tirant lo Blanch, Valencia, 1998, p. 19.

${ }^{13}$ Artículos 58 y 67 y ss. de la Ley de Productividad y Competitividad Laboral. ${ }^{14}$ Cfr. Sempere Navarro, Antonio (Dir.) y Martín Jiménez, Rodrigo (Coord.), Ob. Cit., p. 122.
} 
quedando excluidos los incrementos de actividad que responden a necesidades estructurales de la empresa ${ }^{15}$. Estos contratos, en consecuencia, serán temporales o eventuales aunque tengan que ver con tareas relacionadas con las actividades propias de la empresa ${ }^{16}$.

Asimismo, como ya se dicho, estos contratos tienen que tener el carácter de imprevisibles y responder a variaciones sustanciales de la demanda. Por lo tanto, debe existir, la imposibilidad de prever la ampliación sustancial de la demanda en el mercado. Por ejemplo, la guerra civil desatada últimamente en Libia, ha originado por parte de los grandes consumidores de petróleo como China y Estados Unidos un aumento en su demanda dirigida al resto de países productores de este hidrocarburo, entre los cuales se encuentra Perú, por lo que, la empresa estatal, Petro Perú, dedicada al transporte, refinación, distribución y comercialización de combustibles y otros productos derivados del petróleo, puede ver incrementada inesperadamente su demanda y de forma lo suficientemente significativa como para que su personal permanente no pueda cubrir con las expectativas de sus consumidores.

Es evidente que dada la naturaleza empresarial de este tipo de contratos, su ámbito de aplicación sea únicamente las empresas estatales dado que las características que se necesitan para que estos contratos puedan celebrarse no podrán ser satisfechas en una Administración pública no empresarial.

\subsection{Contrato por inicio o incremento de actividad}

El artículo 57 de la Ley de Productividad y Competitividad Laboral señala que el contrato por inicio o incremento de nueva actividad es aquel que celebrado entre un empleador y un trabajador originados por el inicio de una nueva actividad empresarial siendo su duración máxima de tres años, entendiendo por nueva actividad tanto el inicio de actividad productiva como la posterior instalación o apertura de nuevos establecimientos o mercados así como el inicio de nuevas actividades o incremento de las ya existentes dentro de la misma empresa.

Hasta hace unos años la Ley 32/1984 y posteriormente la Ley 11/1994, el Real Decreto 2546/1994 y el artículo 15 del Estatuto de los Trabajadores español regulaban como contrato temporal de carácter estructural (junto a la clásica tripleta de obra o servicio, interinidad y eventualidades) el celebrado para el lanzamiento de nueva actividad ${ }^{17}$. La relación jurídica originada a través de este contrato tenía como sujeto empleador a las empresas de nuevo establecimiento, o aquéllas ya existentes que amplíen sus actividades a causa del lanzamiento de una nueva línea de producción, un nuevo producto o servicio, o por la apertura de un nuevo centro de Trabajo. Su duración era de entre seis meses y tres años prorrogables mediante acuerdo por

\footnotetext{
15 Ibidem.

${ }^{16}$ Camps Ruiz, Luis Miguel, Ob. Cit., p. 19.

${ }^{17}$ Cfr.Sempere Navarro, Antonio, "Contratos por lanzamiento de actividad», Actualidad Jurídica Aranzadi, N570,2003, en sitio web Aranzadi westlaw.es, última actualización del ubicado el 02 de junio de 2011,URL: http://www.westlaw.es/wles/app/nwles/document?docguid=18c05d78090
}

períodos no inferiores a seis meses, sin que se superen los tres años. Este contrato fue derogado mediante Real Decreto Ley 8/1997secundado por la Ley 63/1997, las causales argüidas para dicha derogación se centraron en el fomento de la contratación indefinida dada la continua desnaturalización que se producía en este tipo de contratación ${ }^{18}$.

El contrato por inicio o incremento de actividad tiene el inconveniente de ser tan abierto que deja la posibilidad de incluir dentro de él múltiples actividades productivas como por ejemplo la apertura de un nuevo mercado dónde el empleador ya tiene una solución para la contratación en el contrato de necesidad de mercado o de obra o servicio específico; la necesidad de propaganda para la empresa también podría ser considerada como inicio de actividad, pero resultaría mejor contratar a través del contrato de ocasión, con el fin de evitar la duración de un contrato tan largo que podría generar la desnaturalización del mismo.

La nueva actividad en el caso de las administraciones públicas podría presentarse frente a las necesidades de personal ante un convenio de cooperación institucional que requiera de la administración realizar actividades específicas de duración determinada hasta de tres años.

Por otro lado, en lo que respecta al incremento de actividades ya existentes, se entiende que este se produce sobre actividades antiguas, y en tanto la norma no hace distinción de ninguna clase se entiende que se refiere a las actividades de naturaleza permanente, pero que por diversas circunstancias han acumulado significativamente siendo, muy difícil o incluso imposible que la persona que venía desarrollando la actividad logre cubrir las expectativas de producción en su trabajo.

Este contrato, al igual que el contrato por necesidad del mercado, se asemeja también al contrato eventual por las circunstancias de la producción español y se encuentra regulado en los artículos 15.b) del Estatuto de los Trabajadores. El contrato eventual prevé la contratación de trabajadores por tiempo determinado cuanto «las circunstancias del mercado, acumulación de tareas o exceso de pedidos así lo exigiera, aun tratándose de la actividad normal de la empresa» ${ }^{19}$.

He aquí justamente la diferencia entre el contrato por necesidades del mercado y el contrato por incremento de actividad. Mientras el primero requiere necesariamente la existencia de una causal objetiva de mercado verificable, la existencia de una excesiva demanda de los productos generados por la empresa; el contrato por incremento de actividad se refiere a una acumulación de tareas que sería imposible de cubrir por el personal permanente de la empresa. Así, como puede observarse de la lectura del artículo 15 . b) lo que ha hecho la legislación peruana es subdividir el contrato eventual en dos partes, el contrato por

\footnotetext{
$\underline{\text { 5311dba876010000000000\&srguid }=i 0 a d 6007900000130513 e 8 f 4424 b c 29 c}$ $\underline{0}$

$\overline{18}$ Vid. Cavas Martínez, Faustino, «El principio de estabilidad en el empleo: crisis claves para su recuperación", Revista del Ministerio de Trabajo y Asuntos sociales, $\mathrm{N}^{\circ} 58,2005$, pp. 122-123.

${ }^{19}$ En los mismos términos se expresa el art. 3.1-1 Real Decreto 2720/1998.
} 
necesidad del mercado y el contrato por incremento de actividad.

Producida esta subdivisión, en el caso de las contrataciones empresariales privadas la línea divisoria entre estos dos contratos es casi inexistente debido a que generalmente la acumulación de trabajos o tareas en las áreas de producción de las empresas se deben a un incremento en la demanda del mercado por ello un gran sector de la doctrina científica peruana no ha dudado en considerar a este tipo de contratación temporal, desvirtuada ${ }^{20}$.

Sin embargo, en el caso de las Administraciones públicas, la diferencia sí que parece evidente. Salvo el caso de las empresas públicas, la Administración pública no tiene como guía o motor de su funcionamiento los índices económicos de oferta y demanda, por el contrario son factores políticos, sociales o incluso coyunturales los que pueden originar una acumulación en determinadas actividades propias de la administración. Por ello, el contrato por necesidades del mercado, dado que tiene como requisito la existencia de un real incremento de la demanda quedará reservado para las empresas públicas que en todo caso podrán acreditar fehacientemente la necesidad de esta contratación. Por el contrario, los contratos de incremento de actividad podrán ser utilizados por las Administraciones públicas cuyo modelo de actuación no son las reglas de la oferta y la demanda, sino la evidente existencia de una acumulación de actividades en una determinada área de la administración.

Esto porque en el caso de la Administración pública peruana, como en cualquier otra, no es extraño que por circunstancias ajenas a ella, generalmente producidas por una coyuntura histórico - política, determinadas actividades se vean incrementadas. Así, muchas veces, la victoria inesperada de un proceso administrativo o judicial hace que los despachos judiciales o de resolución de procedimientos administrativos, se vean abarrotados de casos similares, que hacen imposible que la persona o las personas que habitual y normalmente se dedican a proveer los mismos puedan cumplir satisfactoriamente con los plazos establecidos. Por ejemplo, una vez que el Tribunal Constitucional peruano ${ }^{21}$ reconoce que el concepto remunerativo a tener en cuenta para la bonificación por 25, 30 o 35 años de servicios prestados al sector educativo de la Administración pública era la Remuneración Integra o Total ${ }^{22}$ y no la Remuneración Total Permanente ${ }^{23}$, las solicitudes administrativas y demandas judiciales reclamando el reconocimiento de este beneficio, aumentaron por miles. Otro caso parecido se produjo cuando el Gobierno peruano reconoce que muchos de los despidos realizados en las Administración pública durante el gobierno del Presidente Alberto Fujimori atentaron contra los derechos fundamentales de los trabajadores por la existencia

${ }^{20}$ Cfr. Arce Ortíz, Elmer, Estabilidad laboral y contratos temporales, Pontificia Universidad Católica del Perú, Lima, 2006, p. 26.

${ }^{21}$ STC Exp. № 3360-2003-AA/TC de 21 de abril de 2004: "que el pago de la asignación que se reclama deberá efectuarse en función de la remuneración total y no sobre la base de la remuneración total permanente, conforme está establecido en el inciso b) del artículo $8^{\circ}$ del Decreto Supremo $N^{\circ}$ 051-91PCM".

${ }^{22}$ Constituida por la remuneración total permanente y los conceptos remunerativos adicionales otorgados por Ley expresa, los mismos que se de procedimientos indebidos, calificando los despidos como irregulares o improcedentes, abriéndose la posibilidad de aperturar procedimientos ante el Ministerio de Trabajo, para la revisión de los despidos de los afectados. Siendo aproximadamente 300 mil peruanos en esta situación, las solicitudes que tuvo que afrontar la Administración pública desbordaron sus capacidades logísticas y de personal.

En estos casos es evidente la necesidad de contratar personal adicional al existente frente el incremento de la actividad a través del contrato por incremento de actividad o eventual por circunstancias de la producción.

\subsection{Contrato de reconvención empresarial}

De acuerdo a lo establecido en el artículo 59 de la Ley de Productividad y Competitividad Laboral el contrato de reconvención empresarial es el celebrado en virtud de la sustitución, ampliación o modificación de las actividades desarrollas de la empresa y en general toda variación de carácter tecnológico en la maquinarias, equipos e instalaciones, medios de producción, sistemas, métodos y procedimientos productivos o administrativos. Su duración máxima es de dos años.

Aunque el artículo $59^{\circ}$ no lo mencione, se entiende que las reformas organizativas o tecnológicas a las que se refiere deben tener suficiente entidad para hacer necesaria la contratación de nuevos trabajadores. Así por ejemplo, la implementación del nuevo Sistema Integrado para la administración financiera del Estado (SIAF) significó la ocasión propicia para contratar personal por este tipo de contratación sujeta a modalidad.

\section{CONTRATO DE NATURALEZA ACCIDENTAL}

\subsection{Contrato ocasional}

De acuerdo a lo establecido en el artículo $60^{\circ}$ de la Ley de Productividad o Competitividad Laboral el contrato ocasional o también llamado accidental es aquel celebrado para atender las necesidades transitorias distintas de la actividad habitual del centro de trabajo con una duración máxima de 6 meses al año.

El contrato ocasional, se caracteriza por operar en la actividad no habitual o extraordinaria ${ }^{24}$, por ello se descarta que exista personal abocado a satisfacer el tipo de actividades de las que será objeto el contrato dado que su terreno de acción son las situaciones coyunturales, eventuales o transitorias de la empresa, que generalmente provienen de hechos de repetición cíclica como, por ejemplo, la necesidad de hacer mantenimiento cada tres meses de las computadoras de alguna Administración pública. También es posible que se origine por un imprevisible interés de la administración en

dan por el desempeño de cargos que implican exigencias distintas a las comunes. Art. 9o del Decreto Supremo № 051-91-ED.

23 Constituida por la remuneración principal, bonificación personal, bonificación familiar, remuneración transitoria para la homologación y la bonificación por refrigerio y movilidad. Art. 9o del Decreto Supremo № 05191-ED.

${ }^{24}$ Arce Ortíz, Elmer, Ob. Cit., p. 20. 
formar, instruir o entrenar a su personal con el objeto de conseguir alguna meta o desarrollar estrategias de control de calidad en sus actividades. Así, sucedió, con la generación de modernas administraciones públicas como el Instituto Nacional de Defensa de la Competencia y protección de la Propiedad Intelectual (INDECOPI); dicha administración contrató personal especializado en estrategias coaching para mejorar la calidad de trabajo y atención al público de los servidores y funcionarios públicos de la referida administración, producto de los sorprendentes informes de la Defensoría del Pueblo en torno a la ineficiencia de las administraciones públicas.

La diferencia entre el contrato ocasional y el contrato de obra o servicio específico, es que el contrato ocasional está pensado para obras o servicios intermitentes o de menor entidad, siendo su duración máxima de seis meses.

\subsection{Contrato de suplencia}

El contrato de suplencia es aquel celebrado entre un empleador y un trabajador con el objeto de que éste sustituya a un trabajador estable de la empresa, cuyo vínculo laboral se encuentra suspendido por alguna causa justificada prevista en la legislación vigente o por efecto de disposiciones convencionales aplicables en el centro de trabajo. Así lo establece el artículo 61 de la Ley de Productividad y Competitividad Laboral, señalando además que su duración será la que resulte de la necesidad de las circunstancias.

En este caso nos encontramos frente al supuesto en el cual el empleador reserva el puesto a su titular quien conserva el derecho a la readmisión en la empresa por lo que, operada su readmisión oportuna, se produce la extinción del contrato de suplencia. Por ello, no debe confundirse la vigencia del derecho a reserva de puesto de trabajo y el hecho sustitutorio propiamente dicho, - puesto que la primera se refiere al presupuesto jurídico que asiste al sustituido para reintegrarse en su puesto de trabajo finalizada su ausencia; y el segundo se configura como el presupuesto material que al provocar la ausencia del trabajador, permite la celebración de un contrato de suplencia ${ }^{25}$.

Al contrato de suplencia se le conoce en el ordenamiento jurídico español como contrato de interinidad por sustitución y se encuentra regulado en el artículo 15 inciso c) del Estatuto de Trabajadores que señala que "Cuando se trate de sustituir a trabajadores con derecho a reserva del puesto de trabajo, siempre que en el contrato de trabajo se especifique el nombre del sustituido y la causa de sustitución".

Asimismo el artículo el artículo 8 del Real Decreto 2720/1998, de 18 de diciembre (RCL 1999, 45), reglamento que desarrolla el artículo 15 del Estatuto de los Trabajadores (RCL $1995,997)$ en materia de contratos de duración determinada,

\footnotetext{
${ }^{25}$ Barreiro González, Germán, La sustitución del trabajador con derecho a reserva. El contrato de interinidad, Civitas, Madrid, 1986, p. 44 y ss.

${ }^{26}$ Alzaga Ruiz, Icíar, "La extinción del contrato de interinidad propio cuando el trabajador sustituido de baja por incapacidad temporal es declarado afecto de incapacidad permanente total o absoluta", Aranzadi Social, № 13, 2001, pp. 40-46.

${ }^{27}$ Ibidem..

${ }^{28}$ STSJ Madrid 8 de septiembre 2010 (JUR 2010\343926)
}

señala que «el contrato de interinidad [por sustitución] se extinguirá cuando se produzca cualquiera de las siguientes causas:

a. La reincorporación del trabajador sustituido.

b. El vencimiento del plazo legal o convencionalmente establecido para la reincorporación.

c. La extinción de la causa que dio lugar a la reserva del puesto de trabajo

En consecuencia si el trabajador sustituido se reincorpora a la empresa, el contrato de interinidad se extingue y, si dicha reincorporación no se produce, el contrato de interinidad subsistirá, salvo que el trabajador sustituido pierda el derecho a la reserva de su puesto de trabajo ${ }^{26}$. Así la ausencia de un trabajador con derecho a reserva de puesto de trabajo justifica el recurso a esta modalidad contractual y, al mismo tiempo, determina la duración del contrato, pues la relación se extingue cuando el trabajador sustituido se reincorpora, pero también cuando aquélla reserva desaparece.

En la normativa, española actual prima el término, frente a la condición de manera que, al cesar la circunstancia que dio lugar a la reserva del sustituido, el empresario puede poner fin a la relación laboral del sustituto, sin que este hecho constituya un despido ${ }^{27}$ y por ello se considera que habiendo perdido un trabajador sustituido el derecho a reserva de su puesto de trabajo, el trabajador sustituto que cubría ese puesto de trabajo reservado debe cesar ${ }^{28}$.

En Perú, por el contrario, el contrato queda sujeto a una condición resolutoria en la medida en que su duración "será la que resulte necesaria según las circunstancias" ${ }^{29}$ dado que el artículo $77^{\circ}$ de la Ley de Productividad y Competitividad Laboral dispone que en el caso de los contratos de suplencia estos se considerarán como de duración indeterminada, si el titular del puesto sustituido, no se reincorpora vencido el término legal o convencional y el trabajador contratado continuare laborando. Por lo que, la única causa de resolución contractual es la reincorporación del trabajador suplente, si esta reincorporación no se produce (por ejemplo, por el vencimiento del plazo legal o convencionalmente establecido para la reincorporación del trabajador titular) el trabajador sustituto adquiere automáticamente la calidad de permanente o indefinido, incorporándose a la plantilla de la empresa ${ }^{30}$.

Por otro lado, es interesante detenernos en una figura jurídica que no se encuentra prevista en la normativa peruana, pero que el ordenamiento jurídico español ha desarrollado con detenimiento, nos referimos a los contratos de interinidad por vacante.

\footnotetext{
${ }^{29}$ El artículo 77 del Reglamento de la Ley de Productividad y Competitividad Laboral, Decreto Supremo N001-96-TR, exige que el contrato de suplencia tenga una fecha de extinción pero al no considerarlo la ley esta norma deviene en ilegal e inconstitucional porque el reglamento sólo complementa las leyes sin modificarlas, transgredirlas, ni desnaturalizarlas. El artículo en mención modificaría la ley y en consecuencia no puede considerarse constitucional.

${ }^{30}$ Arce Ortíz, Elmer, Ob. Cit., p. 24.
} 
El artículo 4.1. Real Decreto 2720/1998 agrega una nueva causal del contrato de interinidad completando la fórmula del artículo 15.1. c. del Estatuto de Trabajadores, añadiendo un segundo supuesto: contrato de interinidad para cubrir temporalmente un puesto de trabajo mientras dure el proceso de selección o promoción para su provisión definitiva.

El contrato de interinidad por vacante, surge en función de situaciones frecuentes en la Administración pública en tanto que se utiliza mientras dure un proceso de selección o promoción hasta la cobertura del puesto de trabajo, dado que otras figuras contractuales, le resultan inaplicables; así por ejemplo el contrato de obra o servicios específico se caracteriza por la realización de actividades de naturaleza no permanente, mientras que aquí se estaría cubriendo temporalmente una actividad realizada ordinariamente por la administración ${ }^{31}$.

Este contrato debe formalizarse por escrito haciendo constar la identificación del puesto de trabajo cuya cobertura definitiva se producirá tras el proceso de selección externa o promoción interna, esto en razón de que la causa que fundamenta la contratación temporal reflejará en la presencia de una vacante, "la razón de su existencia"32, por lo tanto la especificación de la plaza constituye, así pues, una verdadera condición (requisito esencial) para la validez de esta vía contractual, no en vano en el propio concepto de interinidad se halla inserta la necesidad de una sustitución, como situación vicaria de una titularidad reservada respecto de una vacante preexistente y todavía no cubierta por la vía regular ${ }^{33}$.

Además en el ámbito de la Administración pública, la duración del contrato de interinidad para la provisión de puesto de trabajo, coincidirá con el tiempo que dure el proceso de selección o promoción interna conforme a lo previsto en su normativa específica, sin que exista límite alguno en la duración de máximos de dicho contrato.

Dada la obligatoriedad en la legislación peruana de contar con un procedimiento de concurso público de méritos para ingresar a la Administración pública independientemente del régimen jurídico laboral público o privado, la posibilidad de la existencia de esta contratación tendría por dificultad que para contratar a una persona por vacante que se caracteriza por tener un proceso de selección o de ingreso a la administración inconcluso, tendría que realizarse un proceso adicional para concursar a ese puesto aún no ocupado por proceso regular, lo cual no tendría ningún sentido. Sin embargo, dada la necesidad de la administración de contar con este personal, no deja de ser interesante la figura, que aprobada mediante una norma legal, habilitaría, a que sin efectuarse concurso alguno, aunque garantizando siempre,

\footnotetext{
${ }^{31}$ Vid. Sempere Navarro, Antonio y Quintanilla Navarro, Raquel, Ob. Cit., p. 89 y ss.

32 Rodríguez Ramos, Patrocinio, El contrato de interinidad por vacante, Editorial Tirant lo Blanch, Valencia, 1996, p. 46.

${ }^{33}$ Fernández Domínguez, Juan José y Rodríguez Escanciano, Susana, Hacia un nuevo régimen jurídico del personal al servicio de las Administraciones
}

un proceso de selección justa, cubriese las plazas en las condiciones expuestas anteriormente.

Cabe aclarar, que esta modalidad contractual no puede ser utilizada para puestos de trabajo vacantes que estén clasificados como de naturaleza administrativa, hasta su provisión definitiva de funcionario de carrera o, en su caso estatutario. Ello es debido a que los puestos funcionariales deben ser desempeñados necesariamente por funcionarios públicos de carrera o, en su caso interinos, pero no por personal laboral ${ }^{34}$.

Por último, es necesario deslindar, aunque ya se hizo referencia a la dificultad del uso del contrato de interinidad por vacante en la Administración pública peruana, la contratación eventual por circunstancias de la producción o de incremento de actividad por déficit de personal, de este tipo de contratación. La diferencia en el empleo de uno u otro modelo de contratación radica en precisar si las circunstancias que legitima la contratación, esto es, la demanda concreta de mano de obra por tiempo determinado, es genérica y no se relaciona con ninguna plaza concreta, constituyendo en fin una necesidad meramente abstracta de fuerza laboral como ocurre cuando existe déficit de personal, en cuyo caso la modalidad adecuada es la eventual; o si por el contrario, el trabajador contratado personalmente sirve a una plaza concreta o específica que está sin titular hasta que sea nombrado conforme a los procedimientos que le sean aplicables en cuyo caso procedería, en caso de que en alguna oportunidad este contrato pueda llegar a ser aplicable en Perú, el contrato de interinidad por vacante, tal como se señala en la Sentencia del Tribunal Supremo en Unificación de doctrina de 16 de mayo de 1996 (RJ 1995, 2169) ${ }^{35}$.

\subsection{Contrato de emergencia}

El contrato de emergencia es aquél que se celebra para cubrir necesidades promovidas por caso fortuito o fuerza mayor coincidiendo su duración con la emergencia.

Este tipo de contrato sería de gran utilidad para la Administración pública ya que esta se encuentra, muchas veces, abocada a brindar la ayuda necesaria frente a desastres naturales como terremotos, inundaciones, atentados terroristas, entre otras muchas calamidades, por ello esta forma de contratación respondería a esta situación de excepcional y urgente atención.

Los requisitos para que se configure la necesidad de este tipo de contrato son que la administración tenga que estar directamente involucrada con la solución originada por la producción de un caso fortuito o fuerza mayor, por ejemplo que tenga que realizar labores de rescate o apartamiento de escombros, que los sucesos efectivamente sean de naturaleza repentina o de violencia inesperada; por ejemplo en el caso de un conflicto social, el Ministerio de Salud puede

Públicas, Instituto Andaluz de la Administración Pública, Sevilla, 2006, p. 171.

${ }^{34}$ Vid. Sempere Navarro, Antonio y Quintanilla Navarro, Raquel, Ob. Cit., p. 90.

${ }^{35}$ Cfr. Sempere Navarro, Antonio (Dir.) y Martín Jiménez, Rodrigo, (Coord.), Ob. Cit., p. 123. 
verse en la necesidad de contratar mayor número de personal médico: doctores o enfermeras para afrontar los continuos levantamientos populares. Sin embargo, este tipo de contratación no justificaría, por ejemplo, la contratación de personas para usar la violencia con el fin de retener a los insurgentes, para ello deberán operar las fuerzas públicas policiales o militares, respetando siempre la dignidad de las personas involucradas en el conflicto.

Ahora, habría que aclarar, dado que esta forma de contratación de acuerdo a lo estipulado por el artículo $62^{\circ}$ de la Ley de Productividad y Competitividad Laboral coincide en su duración con la emergencia, si debe entenderse por "emergencia", el periodo establecido constitucionalmente, como régimen de excepción, ya sea estado de emergencia (En caso de perturbación de la paz o del orden interno, de catástrofe o de graves circunstancias que afecten la vida de la Nación, cuya duración máxima es de 60 días prorrogables por Decreto Supremo si así lo dispone el Presidente de la República) o de sitio (En caso de invasión, guerra exterior, guerra civil, o peligro inminente cuyo plazo es de plazo correspondiente no excede de 45 días prorrogables con aprobación del Congreso de la República); o los contratos podrían celebrase antes de esta declaración o prolongarse mientras dure de hecho la necesidad producida en razón de la emergencia.

El fin del artículo $137^{\circ}$ de la Constitución Política del Perú es garantizar el retorno del orden público o interno de la zona o zonas afectadas con el desastre natural o el desorden civil lo que ha generado un desorden interno, apreciándose la presencia de un peligro excepcional que amenaza o afecta la seguridad física de la población, por lo que constituye una situación de suma gravedad. Por ello, el efecto directo de la declaración de un régimen de excepción es la suspensión de derechos y el control del orden interno por las Fuerzas Armadas.

La intención del artículo $62^{\circ}$ de la Ley de Productividad y Competitividad Laboral, responde a un fin distinto a cubrir las necesidades extraordinarias, repentinas y urgentes que se producen en virtud de situaciones de caso fortuito o fuerza mayor por lo que no es necesaria la declaratoria de estado de emergencia o de sitio para celebrar este tipo de contrataciones, ni su duración tendrá que responder necesariamente al tiempo establecido por la ley que declara el régimen de excepción, pudiendo ser más amplio que el otorgado por el Estado.

Sin embargo, habría que ser cauteloso para no incurrir en su desnaturalización. Por ello, como todo contrato sujeto a modalidad, el contrato de emergencia, tendrá una fecha exacta de inicio y otra de término, debiendo primar siempre el término contractual pactado en el contrato y no la extensión en el tiempo de la contingencia. En el contrato de emergencia, será necesario, para evitar la resolución automática, por cumplimiento del plazo de contratación, la renovación del mismo. Ello debido a que el artículo 77 de la Ley de Productividad y Competitividad Laboral, no le otorga el efecto de transformación inmediata en indefinido vencido el plazo estipulado tal como ocurre, con el contrato de suplencia frente a la no reincorporación vencido el término legal o convencional del titular del puesto del trabajo que viene desempeñando el suplente ${ }^{36}$.

En Perú, este tipo de relación contractual sería extraña, el Gobierno mediante Decreto de Urgencia N 004-2004, aprobó la contratación mediante este tipo de contrato de personal, para la reconstrucción de bienes públicos en la zona de Mesa Redonda, emporio comercial ubicado en Lima- Perú, donde se produjo un incendio de grandes dimensiones ${ }^{37}$.

\section{Conclusiones}

Teniendo en cuenta, todo lo dicho, queda claro que la forma de contratación temporal que debe utilizar la administración pública para realizar actividades de naturaleza extraordinaria o no permanente es la de los contratos sujetos a modalidad en tanto que aplicables en todas sus formas a las actividades propias que le son propias.

\footnotetext{
${ }^{36}$ En el mismo sentido Arce Ortíz, Elmer. Ob. Cit., p. 26.

${ }^{37}$ Ídem, p. 25.
} 